\title{
DETECÇÃO DE Salmonella spp E Listeria monocytogenes ATRAVÉS DE TÉCNICA DE PCR
}

\author{
Juliana Soares Gonçalves ${ }^{1}$ \\ Ana Paula Cheirubim ${ }^{2}$ \\ Kelly Cristina Tagliari de Brito ${ }^{3}$ \\ Benito Guimarães de Brito ${ }^{1,2,3}$
}

GONÇALVES, J. S.; CHEIRUBIM, A. P.; BRITO, K. C. T. de; BRITO, B. G. de. Detecção de Salmonella spp e Listeria monocytogenes através de técnica de PCR. Arq. Ciênc. Vet. Zool. UNIPAR, Umuarama, v. 17, n. 4, p. 223-226, out./dez. 2014.

\begin{abstract}
RESUMO: A maioria dos casos de doenças transmitidas por alimentos é causada por bactérias como Salmonella spp, Listeria monocytogenes, Campylobacter spp e Escherichia coli, entre outros. A contaminação decorre do consumo de alimentos contaminados preparados sob condições impróprias de higiene, manipulação e conservação. Para a detecção dessas bactérias em alimentos, o método convencional de isolamento é o mais utilizado, porém a técnica é demorada e laboriosa. A Reação em Cadeia da Polimerase (PCR) é um método rápido e sensível na detecção de agentes patogênicos e tem sido bastante estudada e gradativamente empregada nas indústrias de alimentos. O objetivo deste trabalho foi avaliar o limite de detecção da técnica de PCR, para Salmonella spp e L. monocytogenes. O limite para detecção das bactérias foram 2 e 5 UFC para Salmonella spp e L. monocytogenes, respectivamente, demonstrando uma boa sensibilidade da técnica de PCR.
\end{abstract}

PALAVRAS-CHAVE: Biologia molecular. Diagnóstico. Listeriose. Salmonelose.

\section{DETECTION OF Salmonella spp AND Listeria monocytogenes THROUGH PCR}

\begin{abstract}
Most cases of foodborne illnesses are caused by bacteria such as Salmonella spp, Listeria monocytogenes, Campylobacter spp, Escherichia coli, among others. Contamination stems from the consumption of contaminated food prepared under improper hygiene, handling and storage conditions. For the detection of bacteria in food, the conventional isolation method is the most commonly used, but the technique is labor-intensive and time consuming. The Polymerase Chain Reaction (PCR) is a rapid and sensitive method for the detection of pathogen agents, and has been extensively studied and gradually used in food industries. The objective of this study is to evaluate the sensitivity of the PCR method for the detection of Salmonella spp and L. monocytogenes. The threshold for the detection of bacteria was 2 and 5 CFU for Salmonella spp and L. monocytogenes, respectively, presenting a high sensitivity to PCR.
\end{abstract}

KEYWORDS: Isolation. Listeriosis. Molecular biology. Salmonellosis.

\section{DETECCIÓN DE Salmonella spp Y Listeria monocytogenes A TRAVÉS DE LA TÉCNICA DE PCR}

RESUMEN: La mayoría de los casos de enfermedades transmitidas por alimentos es causada por bacterias como la Salmonella spp, Listeria monocytogenes, Campylobacter spp y Escherichia coli, entre otros. La contaminación se produce por el consumo de alimentos contaminados y preparados bajo condiciones inadecuadas de higiene, manipulación y conservación. Para la detección de esas bacterias en alimentos, el método convencional de aislamiento es el más utilizado, pero la técnica es laboriosa y consume mucho tiempo. La Reacción en Cadena de la Polimerasa (PCR) es un método rápido y sensible para la detección de patógenos y ha sido ampliamente estudiado y gradualmente empleada en las industrias de alimentos. El objetivo de este estudio fue evaluar el límite de detección de la técnica de PCR, para L. monocytogenes y Salmonella spp. El límite para detección de las bacterias fueron 2 y 5 UFC para Salmonella spp y L. monocytogenes, respectivamente, demostrando buena sensibilidad a la técnica de PCR.

PALABRAS CLAVE: Biología molecular. Diagnóstico. Listeriosis. Salmonelosis.

\section{Introdução}

As doenças transmitidas por alimentos (DTA's) representam um crescente e relevante problema de saúde pública. As infecções de origem bacteriana, transmitidas por alimentos, são importantes causas de gastroenterites severas, que podem resultar em hospitalizações, complicações e sequelas em longo prazo (HELMS; SIMONSEN; MOLBAK, 2006; GREIG; RAVEL, 2009).
Os alimentos como carnes e derivados, ovos, leite e seus derivados são os mais frequentemente envolvidos em DTA's. Os agentes patogênicos veiculados por esses alimentos são na sua maioria bactérias como Salmonella Enteritidise Typhimurium, Listeria monocytogenes, Staphylococcus aureus, Escherichia coli, Campylobacter spp, entre outros. Na maioria dos surtos de DTA's, a contaminação se dá pela manipulação inadequada e pelo armazenamento incorreto dos alimentos. Hábitos como a má higienização das mãos an-

DOI: https://doi.org/10.25110/arqvet.v17i4.2014.5020

${ }^{1}$ Pesquisador do Laboratório Ecolvet-Análises Veterinárias, Ambientais e de Alimentos Ltda, Londrina-PR.

${ }^{2}$ Pesquisador do Londribio Biotecnologia Indústria e Comércio Ltda. Cambé-PR

${ }^{3}$ Pesquisador do Laboratório de Saúde das Aves e Inovação Tecnológica do Instituto de Pesquisas Veterinárias Desidério Finamor / FEPAGRO, Eldorado do Sul-RS. Autor para correspondência - E-mail: benitobrito@gmail.com 
tes da manipulação dos alimentos, armazenamento sob temperaturas inadequadas e a aquisição de produtos de origem desconhecida e duvidosa são algumas das situações mais frequentes que colocam o alimento e a saúde do consumidor em risco (SILVA, 1999). As DTA's podem exacerbar doenças fatais em pessoas com condições médicas preexistentes, em que crianças, idosos e pessoas em condições imunocomprometidas são geralmente mais vulneráveis e em risco de complicações (BEHRAVESH et al., 2011).

Os diagnósticos microbiológicos são tradicionalmente utilizados para avaliar a segurança de um produto alimentar e para definir critérios de rejeição ou aceitação de um lote de alimentos. No entanto, essa abordagem possui algumas limitações, especialmente para diagnóstico de patógenos que ocorrem em números reduzidos e com distribuição não homogênea (VON BLANKENFELD-ENKVIST et al., 2002; DE BOER; BEUMAR, 1999). Além disso, o período necessário para o diagnóstico, pelo método microbiológicoconvencional, é laborioso e demorado, compreendendo uma das principais razões para a realização de um número cada vez maior de pesquisas utilizando novas técnicas de triagem para a detecção de patógenos como Salmonella e Listeria em alimentos (DICKEL et al., 2005; ANDRADE et al., 2014).

O desenvolvimento de métodos de análise de alimentos, mais rápidos e muitas vezes mais sensíveis do que os métodos tradicionais, vêm se destacando na pesquisa nos últimos anos (VON BLANKENFELD-ENKVIST et al., 2002; PARK et al., 2011). Atualmente os testes moleculares de Reação em Cadeia da Polimerase (PCR) têm se tornado substituto do processo de diagnóstico convencional (ANDRADE et al., 2010).

O presente trabalho teve como objetivo avaliar a sensibilidade da técnica de PCR na detecção de Salmonella spp e Listeria monocytogenes.

\section{Material e Métodos}

Bactérias e meios de cultivo: $S$. Typhimurium (ATCC 14028) e L. monocytogenes (INCQS 00353) foram cultivadas em meio de cultura ágar MacConke you Chromocult Listeria Seletivo Agar Base ALOA e as colônias foram transferidas para caldo BHI (Brain Heart Infusion) e caldo Fraser, respectivamente, e incubadas por 24 horas a $37{ }^{\circ} \mathrm{C}$.

Quantificação de bactérias: A partir dos meios de cultura concentrados com os respectivos patógenos, foram realizadas diluições decimais seriadas. Foi diluído $1 \mathrm{~mL}$ do cultivo concentrado em $9 \mathrm{~mL}$ de solução salina $0,1 \%$, e assim sucessivamente, até chegar a diluição de $10^{-9}$. Alíquotas de $100 \mu \mathrm{L}$ das diluições foram utilizadas para a semeadura em placas de ágar MacConkey e ALOA. As placas foram incubadas a $37^{\circ} \mathrm{C}$ durante 48 horas para posterior contagem das colônias características de Salmonella spp e Listeria monocytogenes (APHA, 2001). As diluições foram utilizadas para os testes moleculares.

Extração de material genético: A extração de DNA foi realizada por meio de fervura. O volume de 1,5 $\mathrm{mL}$ de amostra foi centrifugado por 10 minutos a $5800 \times \mathrm{g}$, e o sobrenadante descartado. Ao precipitado foi adicionado $200 \mu \mathrm{L}$ de água ultra pura estéril. Os tubos foram submetidos à fervura por 10 minutos e em seguida centrifugados novamente por 10 minutos a $5800 \times \mathrm{g}$. O sobrenadante foi transferido para tubos novos e armazenado a $20^{\circ} \mathrm{C}$ até o momento de uso.

Reação em Cadeia da Polimerase: A reação de PCR foi realizada com o intuito de verificar qual a sensibilidade desta metodologia, identificando dentre as suspensões bacterianas avaliadas, a suspensão de menor concentração a qual permite a detecção dos respectivos patógenos. O volume e concentração utilizados para cada reação estão descritos na Tabela 1. Os primers e ciclo de amplificação para Salmonella spp (SANTOS et al., 2001) e L. monocytogenes (BLAIS; PHILLIPPE, 2003) foram utilizados de acordo com o descrito na literatura. Para Salmonella foram utilizados os oligo nucleo tídeos iniciadores 159 (5' GTGAAATTATCGCCACGTTCGGGCAA 3') e 141 (5' TCATCGCACCGTCAAAGG AAC C 3') derivados do gene invA, obtendo uma amplificação de DNA com aproximadamente de $284 \mathrm{pb}$. Para L. monocytogenes foram utilizados os oligo nucleo tídeos iniciadores LmonoF (5' CAT TAG TGG AAA GAT GGA ATG 3') e LmonoR (5' GTA TCC TCC AGA GTG ATC GA $\left.3^{\prime}\right)$ derivado do gene $h l y$, amplificando fragmento de aproximadamente $730 \mathrm{pb}$.

O produto amplificado foi colocado em gel de agarose $1 \%$ para corrida eletroforética (SAMBROOK; FRITCH; MANIATIS, 1989) e posteriormente visualizado no sistema de foto documentação Loccus Biotecnologia ${ }^{\circledR}$ L/Pix-ST por meio do uso do corante GelRed R (Biotium ${ }^{\circledR}$ ) e identificados com base na utilização de padrão molecular 100pb DNALadder (Invitrogen $®)$.

Tabela 1: Volume e concentração dos componentes utilizados para uma reação de PCR para Salmonella spp e L.monocytogenes.

\begin{tabular}{lcc}
\hline Componentes & Salmonella spp. & L. monocytogenes \\
\hline $\begin{array}{l}\text { Mix 2,5 mM MgCl } \\
(2,5 \mathrm{x})\end{array}$ & $6,25 \mu \mathrm{L}$ & $12,5 \mu \mathrm{L}$ \\
$\begin{array}{l}\text { Primer Foward }(20 \\
\text { pmol) }\end{array}$ & $0,2 \mu \mathrm{L}$ & $1,0 \mu \mathrm{L}$ \\
$\begin{array}{l}\text { Primer Reverse (20 } \\
\text { pmol) }\end{array}$ & $0,2 \mu \mathrm{L}$ & $1,0 \mu \mathrm{L}$ \\
$\begin{array}{l}\text { Taq DNA Polimera- } \\
\text { se (5U) }\end{array}$ & $0,15 \mu \mathrm{L}$ & $0,3 \mu \mathrm{L}$ \\
Água ultra pura & $7,2 \mu \mathrm{L}$ & $5,2 \mu \mathrm{L}$ \\
Amostra (DNA) & $1,0 \mu \mathrm{L}$ & $5,0 \mu \mathrm{L}$ \\
\hline
\end{tabular}

\section{Resultados e Discussão}

A salmonelose e a listeriose são um desafio para a saúde pública. O sorotipo Typhimurium de Salmonella é prevalente na Europa e América, e pode estar relacionado à transmissão nosocomial de cepas multirresistentes, principalmente entre pessoas com a imunidade comprometida (HERIKSTAD; MOTARJEMI; TAUXE, 2002). De forma semelhante à $S$. Typhimurium, Listeria monocytogenes também acomete principalmente indivíduos altamente suscetíveis, tais como imuno comprometidos (NORRUNG, 2000). A Salmonella é um patógeno de alta incidência com baixa taxa de mortalidade, e a L. monocytogenes um patógeno de baixa incidência com alta taxa de mortalidade. As doenças causadas por esses patógenos foram as principais causas 
de mortes de pessoas com infecções bacterianas transmitidas geralmente por alimentos no período de 1996 a 2005 (BEHRAVESH et al., 2011).

Os métodos convencionais de isolamento requerem de sete a 10 dias para detecção de L. monocytogenes em alimentos, e de quatro a sete dias para Salmonella spp. Isto inclui etapas de pré-enriquecimento não seletivo, seguido de enriquecimento seletivo e plaqueamento em ágar seletivo e diferencial, além de confirmação bioquímica e sorológica de colônias suspeitas (ALMEIDA et al., 2013). Diante do tempo e trabalho empregados em tal método convencional, a implementação de ferramentas de identificação mais rápida e precisa se faz necessário para indicação de presença ou ausência de L. monocytogenes e Salmonella spp., em diversos produtos alimentares. A utilização de metodologias mais rápidas possibilita o controle de infecções, além de representar uma redução de custos, uma vez que estoques de produtos são liberados somente após os resultados microbiológicos serem conhecidos (ALMEIDA et al., 2013; GÖKSOY; KIRKAN; KAYA, 2006). Em virtude disso, avanços na biotecnologia nas últimas décadas resultaram no desenvolvimento de uma variedade de métodos para facilitar e agilizar o processo de identificação de micro-organismos patogênicos como L. monocytogenes e Salmonella spp, havendo dentre estes, técnicas imunológicas como ELISA e técnicas baseadas em ácido nucléicos, tal como o PCR (GÖKSOY; KIRKAN; KAYA, 2006; FRATAMICO, 2003; LÖFSTRÖM; HANSEN; HOORFAR, 2010).

Neste estudo foi realizada o método de PCR e estabelecido o limite de detecção de Salmonella spp e L. monocytogenes. $\mathrm{Na}$ análise do método molecular foram obtidos fragmentos de DNA com tamanho de 284 pb para Salmonella sppe $730 \mathrm{pb}$ para L. monocytogenes. Foram detectadas 2 UFC para Salmonella spp e 5 UFC para L. monocytogenes.

A literatura mostra que estudos comparando tecnologias imunológicas e de PCR com métodos bacteriológicos padrão nem sempre foram concordantes (ALMEIDA et al., 2013). Em acordo com os resultados obtidos neste estudo, um grande número de relatos na literatura tem demonstrado que a PCR apresenta uma sensibilidade igual ou maior que métodos de culturas tradicionais, e permite a detecção mais rápida de patógenos em amostras alimentares e fecais (GÖKSOY; KIRKAN; KAYA, 2006; FRATAMICO, 2003; SCHRANK et al., 2001; BOLTON et al., 2002; JAMSHIDI; KALIDARI; HEDAYATI, 2010).

Resultado similar foi obtido por Dickel et al.(2005), onde compararam o método microbiológico convencional, ELISA e PCR para detecção de Salmonella spp.em amostras de frango contaminadas artificialmente. Entre as três técnicas, o método microbiológico convencional foi a que detectou o menor número de amostras positivas. Tanto ELISA quanto PCR foram superiores na detecção de $S$. Typhimurium, $S$. Enteritidis e $S$. Gallinarum, com exceção da $S$. Pullorum, onde somente a PCR foi o método mais eficaz, sendo o microbiológico convencional e o ELISA estatisticamente semelhantes.

Shalaby et al. (2011) estudaram 66 amostras clínicas e 100 amostras de alimentos, comparando o método microbiológico convencional de diagnóstico com a PCR para detecção de L. monocytogenes. Verificaram que um total de $7,6 \%$ dos isolados de L. monocytogenes foram identificados tanto pelo método convencional e PCR, em diferentes amostras clínicas. No entanto, a PCR identificou $6 \%$ de $L$. monocytogenes isoladas de produtos alimentares e apenas $4 \%$ dos isolados foram identificados pelo método convencional, concluindo que a PCR é um procedimento rápido, com alta sensibilidade e especificidade, para a detecção e identificação de L. monocytogenes a partir de amostras clínicas e de alimentos.

De forma geral, os estudos mostram que testes baseados em PCR são mais sensíveis que métodos de cultura e ainda, que testes de cultura e PCR são mais específicos que imunoensaios para detecção de Salmonella e L. monocytogenes em alimentos (FRATAMICO, 2003; MESTER; SCHODER; WAGNER, 2014).

O método microbiológico convencional, além de ser bastante laborioso, requer um tempo mínimo de cinco dias para obtenção do diagnóstico, podendo estender-se até sete dias, caso sejam realizados testes bioquímicos complementares e sorologia para determinação do sorovar de Salmonella. Já a técnica de PCR obtém o resultado em até três dias. Assim, a partir dos resultados obtidos foi possível verificar que a técnica de PCR pode ser utilizada no diagnóstico de Salmonella spp e L. monocytogenes pois apresenta umaboa sensibilidade, além de demonstrar maior praticidade que os métodos bacteriológicos convencionais.

\section{Conclusão}

Os resultados obtidos demonstraram que a técnica de PCR mostrou possuir uma boa sensibilidade para a detecção de Salmonella spp e L. monocytogenes. Além disso, a utilização da PCR também apresenta maior praticidade e detecção mais rápida, sendo, portanto, recomendável à utilização desta técnica para a detecção de patógenos em alimentos.

\section{Agradecimentos}

Ao FINEP - Financiadora de Estudos e Projetosdo Programa Subvenção Pesquisador na Empresa projeto ${ }^{\circ}$ 01/08/031900 e CNPq - Conselho Nacional de Desenvolvimento Científico e Tecnológico - Programa Rhae Inovação e Bolsa Produtividade Desenvolvimento Tecnológico e Extensão Inovadora processo312126/2013-1 e 312575/2013-0.

\section{Referências}

ALMEIDA, C. et al. Detection of Salmonella enterica serovar Enteritidis using real time PCR, immuno capture assay, PNA FISH and standard culture methods in differente types of food samples. International Journal of FoodMicrobiology, v. 161, p. 16-22, 2013.

ANDRADE, R. B. et al. Métodos diagnóstico para os patógenos alimentares: Campylobacter sp., Salmonella sp. e Listeria monocytogenes. Arquivo Instituto Biológico, v. 77, n. 4,p. 741-750, 2010.

ANDRADE, R. R. et al. Ocorrência e diferenciação de espécies de Listeria spp. em salsichas tipo hot dog a granel e em amostras de carne moída bovina comercializadas no Distrito Federal. Ciência Rural,v. 44, n. 1, p. 147-152, 
2014.

APHA - AMERICAN PUBLIC HEALTH ASSOCIATION. Compendium of Methods for the Microbiological Examination of Foods. $4^{\text {a }}$ Ed. Washington. 2001.

BEHRAVESH, C. B. et al. Deaths associated with bacterial pathogens transmitted commonly through food: foodborne diseases active diseases surveillance network (foodnet), 1996-2005. The Journal of Infectious Diseases, v. 204, p. 263-267, 2011.

BLAIS, B. W.; PHILLIPPE, L. M. Identification of presumptive positive Listeria monocytogenes from foods and environmental samples by the polymerase chain reaction. Health Canada's. Laboratory Procedure, 2003.

BOLTON, F. J. et al. Detectionof Campylobacter jejuni and Campylobacter coli in foods by enrichment culture and polymerase chain reaction enzyme-linked immunosorbent assay. Journal of Food Protection, v. 65, p. 760-767, 2002.

De BOER, E.; BEUMER, R .R. Methodology for typing and detection of food home microorganisms. International Journal of Food Microbiology, v. 50, p. 119-30, 1999.

DICKEL, E. L .et al. Análise comparativa entre microbiologia convencional, ELISA e PCR para detecção de Salmonella enteritidis, S. typhimurium, S. gallinarume $S$. pullorum em carne de frango contaminada artificialmente.

Revista Brasileira de CiênciaVeterinária, v. 12, n. 1/3, p. 5-10, 2005

FRATAMICO, P. M. Comparison of culture, polymerase chain reaction (PCR) TaqMan Salmonella, and Transia Card Salmonella assays for detection of Salmonella spp. in naturally contaminated ground chicken, ground turkey, and ground beef. Molecular and Cellular Probes, v. 17, p. 215 221, 2003.

GÖKSOY, E. Ö.; KIRKAN, S.; KAYA, O. Comparison of polymerase chain reaction and convencional methods for the diagnosis of Listeria monocytogenes in stuffed mussels. Turkish Journal of Veterinary \& Animal Sciences, v. 30, p. 229-234, 2006.

GREIG, J. D.; RAVEL, A. Analysis of foodborne outbreak data reported internationally for source attribution.

International Journal of Food Microbiology, v. 130, p. 77-87, 2009.

HELMS, M.; SIMONSEN, J.; MOLBAK, K. Foodborne bacterial infection and hospitalization: a registry-based study. Clinical Infectious Diseases, v. 42, p. 498-506, 2006.

HERIKSTAD, H.; MOTARJEMI, Y.; TAUXE, R. V. Salmonella surveillance: a global survey of public health serotyping. Epidemiology \& Infection, v. 129, p. 1-8, 2002.
Isolation and identification of Salmonella Enteritidis and Salmonella Typhimurium from the eggs of retail stores in Mashhad, Iran using conventional culture method and multiplex PCR assay. Journal of Food Safety, v. 30, p. 558-568, 2010.

LÖFSTRÖM, C.; HANSEN, F.; HOORFAR, J. Validation of a 20-h real-time PCR method for screening of Salmonella in poultry faecal samples.Veterinary Microbiology, v. 144, p. 511-514, 2010.

MESTER, P.; SCHODER, D.; WAGNER, M. Rapid sample preparation for molecular biological food analysis based on magnesium chloride. Food Analytical Methods, v. 7, p. 926-934, 2014

NORRUNG, B. D. V. M. Microbiological criteria for Listeria monocytogenes in foods under special consideration of risk assessment approaches. International Journal of Food Microbiology, v. 62, p. 217-221, 2000.

PARK, S. H. et al. Multiplex PCR assay for the detection and quantification of Campylobacter spp, Escherichia coli O157:H7 and Salmonella serotypes in water samples. FEMS Microbbiology Letters, v. 316, p. 7-15, 2011.

SANTOS, L. R. et al. Identificação de Salmonella através da Reação em Cadeia pela Polimerase (PCR). Arquivos da Faculdade de Veterinária, p. 29, p. 87-92, 2001.

SILVA, J. A. As novas perspectivas para o controle sanitário dos alimentos. Revista Higiene Alimentar, v. 12, n. 65, p. 19-24, 1999.

SAMBROOK, J.; FRITCH, E. F.; MANIATIS, T. Molecular cloning: A Laboratory Manual. New York: Cold Spring Harbor Laboratory Press, 2ed, 1989.

SCHRANK, I. S. et al. Influence of enrichment mediaand application of a PCR based method to detect Salmonella in poultry industry products and clinical samples. Veterinary Microbiology, v. 82, p. 45-53, 2001.

SHALABY, M. A. et al. Comparison of polymerase chain reaction and conventional methods for diagnosis of Listeria monocytogenes isolated from different clinical specimens and foodstuffs. Medical Microbiology \& Immunology, v. 57, n. 11/12, p. 919-924, 2011.

VON BLANKENFELD-ENKVIST, G.; BRÄNNBACK, $M$. Technological trends and needs in food diagnostics. National Technology Agency, 2002.

Recebido em: 10 Dez. 2014 Aceito em: 29 Dez. 2014

JAMSHIDI, A.; KALIDARI, G. A.; HEDAYATI, M. 